\title{
APÓS A MAÇÃ...
}

\author{
Amazonita Alfaia Esashika*
}

\section{Gordon, Richard. A Assustadora História do Sexo. São Paulo: Ediouro. 2002. 367p}

A Assustadora História do Sexo é, antes de tudo, um livro bemhumorado. Com um olhar panorâmico, o autor parece usar uma câmera, bisbilhotando o passado e o futuro à procura de algo assustador na história da sexualidade dos ingleses. Faz uma narração metódica dos fatos notáveis, da interferência da sexualidade na vida dos povos que os ingleses colonizaram, e conseqüentemente em toda humanidade. Às vezes com a cientificidade da linguagem médica, outras reproduzindo o pensamento de alguns autores contemporâneos. Revela detalhes sobre a vida sexual de personagens importantes da história como a Rainha Elizabeth, Napoleão, entre outros.

0 autor foi muito feliz em começar e terminar sua obra com uma fábula, porque este tipo de narrativa costuma seduzir os leitores e fazer refletir diante das imagens simbólicas e metáforas.

No capitulo 0 Começo ele cita o Gênesis, a criação do universo e dos seres vivos é como se usasse como protagonista, um Deus, um tanto ingênuo, que cria uma empresa com um fim em si, e depois descobre

*Psicóloga, Pós-graduada em Educação e Terapia Sexual Humana pela SBRASH e pela Faculdade de Medicina do ABC. Professora e Terapeuta Sexual da Faculdade de Medicina em Psicossomática e Sexualidade Humana. 
atônito que ela enredou por outros rumos. Ao dar ordens para os funcionários do Jardim do Éden: "Crescei e multiplicai-vos" não se deu conta, que nós, seres humanos, não íamos fazer a cópula como dois seres inferiores, sem prazer. Esqueceu de que o encontro entre os humanos tem peculiaridades, e gera misturas que não haviam sido programadas. 0 surgimento do amor, o envolvimento, o olhar que só os amantes sabem dar, o afago, o tesão, surpreendeu-o, com certeza. Sexo era mais diversão do que procriação. Não previu que Evas poderiam gostar de Evas e Adãos de Adãos. Percebeu que os Adãos podiam tornarse bobos, paranóicos, ciumentos, criminosos passionais, para agradar e seduzir suas Evas, e que estas poderiam gastar todo dinheiro dos homens em roupas para seduzi-los. E se o homem excluisse os mandamentos 6 , 7, 9 e 10? Mas, também Deus havia lhes dado o livre arbítrio! Parece que o autor propõe uma jornada lúdica, tomando Deus como um voyeur que não perde de vista a sexualidade humana, acompanhando toda a evolução sexual dos ingleses até os dias de hoje.

Em Território Virgem o autor sugere que por vezes temos idéias surpreendentes, e por medo de ser taxados de loucos, ou por temor, não a colocamos em prática ou as descrevemos nos livros. Cita a inversão da comida pelo sexo, sugerida por André Maurois, que talvez estivesse cansado de tanta nudez, ou que achasse que comer era melhor que fazer sexo. 0 resultado disso seria que provavelmente as mulheres ambiciosas copulariam livremente com seus chefes, mas almoçariam com eles em segredo. Um homem convidaria informalmente uma moça para ir para a cama, mas um convite para jantar requeriria cálculo e persuasão.

Gordon passa a descrever como a sexualidade foi sendo entendida ao longo da história inglesa. Que a Igreja declarou imoral a paixão, a menos que fosse aplicada ao propósito da reprodução. A castidade passou a fazer parte das obrigações de padres, monges e freiras. Era tão entusiasta da virgindade que para guardá-la construiram-se belos conventos, em terrenos cercados por muros altos que abrigavam filhas de familias nobres e donos de terras. 0 casamento é um marco enganoso no território virgem, foi baseado não no sexo e sim no dinheiro. Para as famílias desprovidas de bens, o casamento era dispendioso e as pessoas se juntavam e se separavam 
ao seu bel prazer. A Igreja pôs a mão no casamento no século XIII . Nascer de uma virgem é uma estranha idéia. 0 episódio bíblico foi uma ficção da Igreja que, muito escrupulosamente não poderia permitir que Jesus nascesse de uma atividade tão rude como a cópula.

0 autor segue constatando que, diante do número de casamentos e de divórcios na atualidade, homens e mulheres, sexualmente essenciais uns para os outros, são inadequados para a vida em comum. Sugere que o ideal romântico tem origem na Era do Cavalheirismo, quando as virgens eram resgatadas dos dragões por cavaleiros errantes. No entanto os sentimentos de compaixão, sacrifícios e honras e fidelidade, tinham sempre motivação sexual implícita, além de fomentar uma esfera machista, colocando a mulher numa posição passiva mesmo que fosse princesa, filha do rei.

Em Nossa Virgem Rainha, Gordon descreve como o império britânico normatizou a sexualidade. Faz um relato irônico, tomando a Rainha Elizabeth como uma mulher que teve vários relacionamentos desde a idade de 14 anos com parceiros de 40 , sendo que quanto mais aumentava a sua idade, a de seus parceiros ia diminuindo. Assim, aos 53 tinha parceiros de 20 anos. Relata que circulava entre os embaixadores da corte de Elizabeth que ela não poderia ter filhos, e nem mesmo fazer sexo porque sofria de uma abertura vaginal congenitamente estreita, ou de vaginismo de origem psicológica. Seu trunfo político era fazer de sua virgindade um orgulho nacional.

0 império britânico se espalhou pelos trópicos e a troca de favores sexuais com as nativas, como acontece até hoje, era muito comum. Achavam que as prostitutas do Oriente eram mais limpas, sabiam cantar, vestiam-se melhor e eram mais inteligentes (principalmente as japonesas), mais passivas. Ensinavam-lhe a própria lingua, ao que eles chamavam de "dicionário na cama".

Em 1756 os ingleses começaram a dominar a Índia. Em 1890 o número de soldados das tropas estacionadas na Índia com doenças venéreas, era de 438 para mil, significando a propagação na época de sífilis e gonorréia. As prostitutas em sua maioria estavam contaminadas com uma ou ambas as doenças. Fazer sexo com elas era uma "roleta-russa". 
No entanto o autor nos chama a atenção sobre como a imprudência diante do perigo era uma qualidade militar apreciada. A homossexualidade era considerada uma aberração. Rhodes, o principal construtor do império e Baden Poweel, o principal escoteiro eram homossexuais. Em 1885, no Oceano Índico, em Uganda, 31 rapazes e meninos foram mortos por apresentarem condutas homoeróticas. Neste contexto a masturbação era encarada como causa de enlouquecimento. Na metade do século XVIII, surgiu a camisinha. Diz-se que Casanova já a conhecia, que as soprava e afagava pelo quarto como balões, levando suas companheiras a grandes gargalhadas. Enquanto usamos a expressão "chupar bala com papel", eles usavam "lavar os pés sem tirar as botas". Gordon revela dados interessantes sobre a vida sexual de Napoleão. Conta que um médico fez uma observação sobre ele, após sua morte: "Na verdade todo seu corpo era pequeno e efeminado. 0 púbis lembrava muito o "Mons Veneris" das mulheres. Os músculos do peito eram pequenos, os ombros estreitos e os quadris largos". Por ter astúcia feminina foi muito bom estrategista. No outono de 1795 conheceu Rose, não gostando de seu nome chamou-a de Josephine. Era casada com um Visconde de quem se separou tornando-se amante do Conde de Barras. Este, desejando se livrar dela, prometeu-a a Napoleão, e também como presente de casamento o comando das armas da Itália. Napoleão escrevia cartas todos os dias para ela. Gordon destaca uma frase estranha em uma dessas cartas: “Estou chegando amanhã, não lave". Em 1798, ele escreveu ao irmão expressando a infidelidade de Josephine. Napoleão teve várias mulheres e morreu sem esposa e amante favoritas.

A Rainha Vitória, após a morte do príncipe Albert, teve também suas histórias amorosas. Foi assediada, protegida e seguida por John Brown, seu servidor escocês por 34 anos. Morreu no castelo de Windsor em 1883, de erisipela complicada por alcoolismo crônico e delirium tremens. Em 1885, as virgens eram os "bons-bocados" do menu sexual. As moças oferecidas a seus clientes tinham de 12 a 15 anos. Liverpool anunciava ter 500 prostitutas com menos de 13 anos.

No ano de 1888, em que os contemporâneos denominavam “o ano dos três oitos" num dia frio de chuva Jack, o Estripador fez sua primeira 
vitima. Todas prostitutas. Gordon nos dá um relato, anatômico de como os cadáveres foram encontrados, parecendo que esteve por lá, fazendo a autópsia. Torna o medo tão verídico que teme que o narrado saia da estória e comece a matar. Jack fez sua última vitima em 9 de novembro do mesmo ano. A polícia vitoriana nunca descobriu Jack, o Estripador.

Correram rumores durante a guerra que Hitler, que lutava pela supremacia da raça ariana por ver seus próprios atributos físicos, tinha uma deficiência genital: era desprovido do testículo esquerdo, tinha 72 pulsações por minuto e sua pressão sanguinea aumentava sobremaneira quando em estado de excitação. 0 septo nasal tinha um ligeiro desvio para a direita e sofria de sinusite, o que provocava uma secreção purulenta. Tinha eczema na canela esquerda e furúnculo na nuca, era gago na adolescência. Parece que teve uma experiência sexual com uma mulher em um estábulo, mas no momento mais importante algo saiu errado e a paixão terminou como um balde de leite derramado. 0 Terceiro Reich terminou em estilo shakespeariano, em uma carnificina suicida com cianeto.

Gordon coloca que a circuncisão tinha fundamentos na idéia de que o clitóris é uma intrusão masculina agressiva, incongruente em uma menina, como o prepúcio é uma intrusão feminina colocada erroneamente no menino.

Nosso autor imagina Deus a olhar como um voyeur os homens depois que os expulsou do paraiso. Vendo que o casamento não foi baseado no sexo, que a castidade, a virgindade e a fidelidade foram usadas com finalidade financeira. Que por trás do cavalheirismo estava o sexo. Que a Rainha Elizabeth poderia ser vaginica, porque seu pai mandara executar sua mãe aos 2 anos e sua madrasta aos 8 anos. A mulher tinha uma membrana que a tornava incapaz para os homens, embora talvez tenha sido adepta do sexo oral, já que para seu prazer experimentou muitos deles. Que existiram nas viagens britânicas 2 mulheres piratas que se camuflaram e uma delas declarou amor a outra revelando seu verdadeiro sexo. Napoleão, muito vaidoso, trajava roupa militar com seus botões, ombreiras, lhe dando um porte elegante e másculo, no entanto teve disfunção erétil situacional. Pelado, revelava 
um corpo efeminado, mas tinha o poder como sua arma de sedução. E Hitler, treinando para guerra, encarcerava jovens moças que ele gostava as impedindo de sair, a ponto de suicidarem. Evas Brauns existem hoje em dia, onde se anulam por causa do amor ou poder.

Gordon termina seu livro com outra fábula, falando sobre o desejo, imaginando que Deus daria como castigo de toda essa forma assustadora, pervertida, variada e às vezes cruel dos homens fazerem sexo, a falta de interesse sexual. Mas, um anjo pede-lhe que deixe pelo menos o sexo pela TV. Sua ironia encontra veracidade nas pesquisas atuais sobre a resposta sexual humana: as estatisticas comprovam que a fase mais comprometida é a fase do desejo, onde tudo começa. Sugerimos que Deus devolva o poder à maçã. Que hoje é um simples alimento salutar e inofensivo, com um cheiro maravilhoso, e que antes era um poderoso afrodisiaco, alucinógeno, narcótico e causador de orgasmos múltiplos e fonte de sabedoria! Que deveríamos dar aos nossos pacientes e às vezes a nós mesmo essa "pílula mágica", procurada por quase todos, principalmente em terapia.

E que Deus se apiede de nossas almas, e nos devolva o Paraíso com maçãs, Adãos e Evas. 